\title{
Characterization of Degradation in Nickel Impregnated Scandia-Stabilize Zirconia Electrodes during Isothermal Annealing
}

\author{
Jingyi Chen, ${ }^{a, z}$ Antonio Bertei, ${ }^{b}$ Enrique Ruiz-Trejo, ${ }^{b}$ Alan Atkinson, ${ }^{a, *}$ \\ and Nigel P. Brandon ${ }^{b}$
}

${ }^{a}$ Department of Materials, Imperial College London, SW7 2AZ, United Kingdom

${ }^{b}$ Department of Earth Science and Engineering, Imperial College London, SW7 2AZ, United Kingdom

\begin{abstract}
This study investigates the stability of nickel-impregnated scandia-stabilize zirconia composite electrodes during isothermal annealing at temperatures from 600 to $950^{\circ} \mathrm{C}$ in a humidified hydrogen atmosphere ( 3 vol \% water vapor). Typically an initial rapid degradation of the electrode during the first $17 \mathrm{~h}$ of annealing is revealed by both an increase in polarization resistance and a fall in electronic conductivity. Secondary electron images show a shift in nickel particle size toward larger values after $50 \mathrm{~h}$ of annealing. The declining electrochemical performance is hence attributed to nickel coarsening at elevated temperatures. Nickel coarsening has two microstructural effects: breaking up nickel percolation; and reducing the density of triple phase boundaries. Their impact on electrode area specific resistance is explored using a physical model of electrode performance which relates the macroscopic electrochemical performance to measurable microstructural parameters.

(C) The Author(s) 2017. Published by ECS. This is an open access article distributed under the terms of the Creative Commons Attribution 4.0 License (CC BY, http://creativecommons.org/licenses/by/4.0/), which permits unrestricted reuse of the work in any medium, provided the original work is properly cited. [DOI: 10.1149/2.0821709jes] All rights reserved.

(cc)BY
\end{abstract}

Manuscript submitted June 6, 2017; revised manuscript received June 26, 2017. Published July 11, 2017.

The solid oxide fuel cell (SOFC) offers both high conversion efficiency and low environmental pollution. ${ }^{1}$ When combined with a bottoming gas turbine generator, the resulting hybrid (SOFC-GT) system is capable of reaching $70 \%$ electrical efficiency. ${ }^{2,3}$ The typical operational temperature for an SOFC is in the range of $600^{\circ} \mathrm{C}$ to $1000^{\circ} \mathrm{C}$, depending on the design and the materials employed. Such high temperature operation makes it possible to use not only hydrogen, but also reformed hydrocarbon fuels, or even unreformed hydrocarbons (direct operation) if nickel-free anodes are employed. ${ }^{4,5}$ By recovering the waste heat, SOFCs can be used as a combined heat and power (CHP) unit with high electrical and total efficiencies. ${ }^{6,7}$

At the SOFC anode, gaseous fuel molecules are oxidized by the oxide ions $\mathrm{O}^{2-}$ transported through the electrolyte, giving out electrons to an external circuit. ${ }^{8}$ Nickel-yttria-stabilize-zirconia (YSZ) cermet is the most widely-used SOFC anode material due to its low thermal expansion coefficient mismatch with the electrolyte ${ }^{9}$ and the high electro-catalytic activity of nickel..$^{10,11} 8 \mathrm{~mol} \%$ YSZ has an oxygen ionic conductivity of $0.164 \mathrm{~S} \mathrm{~cm}^{-1}$ at a temperature of $1000^{\circ} \mathrm{C}^{12}$ In comparison, $12 \mathrm{~mol} \%$ scandia-stabilize-zirconia (ScSZ) has a higher conductivity of $0.300 \mathrm{~S} \mathrm{~cm}^{-1}$ at $1000^{\circ} \mathrm{C}^{13}$ and is preferable to YSZ for SOFCs working in the lower range of SOFC operating temperatures. ${ }^{14,15}$

Conventionally nickel-based anodes are fabricated by mixing powders of $\mathrm{NiO}$ and the chosen ionic conductor and then reducing the $\mathrm{NiO}$ to $\mathrm{Ni}$ on first use of the cell. However, impregnation of a soluble nickel salt into a preformed ionically conducting porous skeleton has been investigated as an alternative fabrication technique because it gives a finer dispersion of $\mathrm{Ni}$ particles on reduction. ${ }^{16,17}$ This has also been shown to be more redox stable. ${ }^{18}$ Impregnation has been shown to produce electrodes with superior electrochemical performance compared to the conventional route. For example, impregnating $\mathrm{La}_{0.9} \mathrm{Sr}_{0.1} \mathrm{Ga}_{0.8} \mathrm{Mg}_{0.2} \mathrm{O}_{3-\mathrm{d}}$ (LSGM) with nickel produced an electrode with area-specific resistance (ASR) of only $0.008 \Omega \mathrm{cm}^{2}$ at $650{ }^{\circ} \mathrm{C},{ }^{19}$ much lower than the ASR of $0.05 \Omega \mathrm{cm}^{2}$ for a similar electrode produced by the conventional route. Impregnation of the nickel salt solution has been shown to produce a well-dispersed nickel network which reduces the anode polarization resistance ${ }^{20}$ and at a lower nickel content as compared to the conventional anode. ${ }^{21}$ With only $14 \mathrm{wt} \%$ $\mathrm{Ni}$, nickel infiltrated gadolinia-doped ceria (GDC) electrodes reached a low ASR of $0.14 \Omega \mathrm{cm}^{2}$ in $50 \% \mathrm{H}_{2}-50 \% \mathrm{~N}_{2}$ at $750^{\circ} \mathrm{C} .^{22}$ A nickel infiltrated YSZ electrode with $15 \mathrm{vol} \%$ nickel loading showed a polarization resistance of $0.25 \Omega \mathrm{cm}^{2}$ at $650^{\circ} \mathrm{C}$ in $97 \% \mathrm{H}_{2}-3 \% \mathrm{H}_{2} \mathrm{O}{ }^{23}$ The

*Electrochemical Society Member.

${ }^{\mathrm{z} E-m a i l: ~ J C 5612 @ i c . a c . u k ~}$ nickel particle size was only $10-100 \mathrm{~nm}$ by the impregnation route. ${ }^{18,23}$ Furthermore, the impregnated electrodes have a better thermal expansion coefficient match to the dense electrolyte which reduces the risk of electrode delamination. ${ }^{24}$

The expected commercial operational life time for an SOFC is 40,000-50,000 hours. ${ }^{25}$ The state-of-the-art nickel based cermet anode suffers from degradation when operating at high temperatures because of coarsening of nickel particles. Nickel coarsening is the agglomeration of nickel particles driven by minimization of the total surface and interface energy. The smaller nickel particles, which have a larger curvature, shrink as nickel is transported to the larger particles which grow. In a nickel cermet anode, oxidation of the fuel takes place at the triple phase boundary (TPB) where nickel, ionic conductor and pore join together. Gaseous fuel and oxidation products are transported in and out through the channels in the porous structure. All three phases need to percolate in the porous composite structure. Chen et al.'s ${ }^{26}$ phase-field simulation revealed nickel coarsening caused a considerable reduction of TPB length within 50 hours. Simwonis et al. ${ }^{27}$ measured a decrease of $33 \%$ in electrical conductivity after annealing a Ni-8YSZ anode cermet for $4000 \mathrm{~h}$ at $1000^{\circ} \mathrm{C}$ which was correlated with an increase in nickel particle diameter from 2.0 to $2.6 \mu \mathrm{m}$.

The electrochemical performance of the SOFC anode has been demonstrated to correlate with the TPB density (length per unit volume). The introduction of nanoparticles via impregnation increases the TPB length in the composite electrode. ${ }^{28}$ However, coarsening of nickel leads to a reduction in the number of nickel particles and therefore a decrease in the percolated TPB length. Similarly break-up of the nickel network caused by the high interfacial energy between nickel and ionic conductor leads to a reduction in the percolation of the network. X-ray tomography images reported by Kennouche et al. ${ }^{29}$ showed a continuous decrease in active TPB density in a $\mathrm{Ni}$ YSZ anode as the average nickel particle size increased from $650 \mathrm{~nm}$ to $950 \mathrm{~nm}$. Simulations of ASR have shown that the ASR is mainly determined by the triple phase boundary density. ${ }^{27,28}$

Though impregnation has been an attractive fabrication route to produce better SOFC electrodes, the stability of the nickelimpregnated electrode still remains a barrier to commercialization. Klemens $\varnothing$ et al. ${ }^{23}$ showed the nickel content is a decisive factor in determining the extent of degradation over time. Attempts were made by Miller et al. ${ }^{30}$ to relate the degradation manifest in anode polarization resistance to nickel particle size via a simple coarsening model. Anodes having scaffolds impregnated with nano-scale particles of copper and ceria have also been reported to have degraded significantly following heat-treatment for $3 \mathrm{~h}$ at $800^{\circ} \mathrm{C} .{ }^{31}$ Therefore in this paper, we study the isothermal degradation of nickel-impregnated ScSZ 


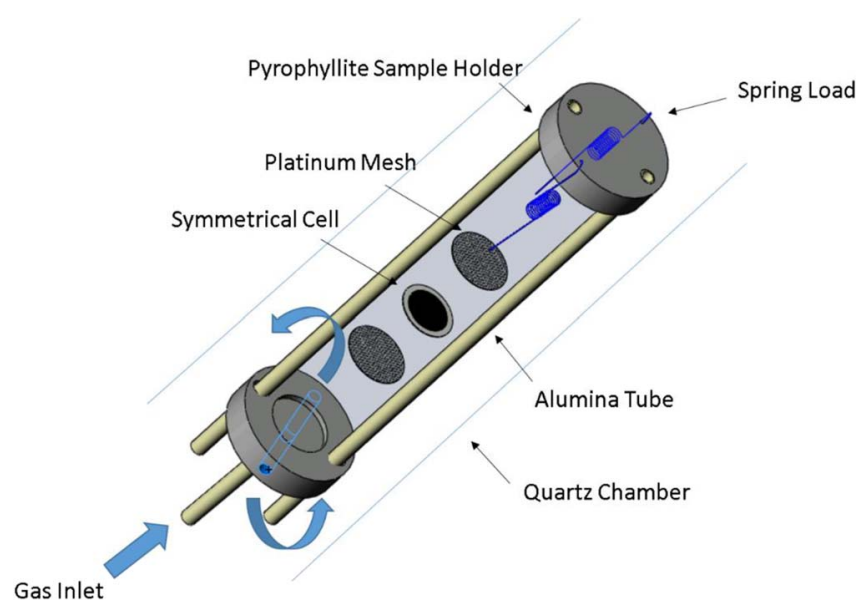

Figure 1. Schematic of the electrochemical test rig. The rig has a single fuel gas inlet and the arrows represent the fuel gas flow paths.

electrode in a reducing atmosphere and present a physical model that analyses the effect of coarsening on electrode performance.

\section{Experimental}

The ScSZ scaffold was prepared by sintering ScSZ powder mixed with carbon black as a pore former. $80 \mathrm{wt} \% \mathrm{ScSZ}$ (fuelcellmaterials Sc10SZ-TC, surface area $8.9 \mathrm{~m}^{2} \mathrm{~g}^{-1}$ ) and $20 \mathrm{wt} \%$ carbon black (Alfa Aesar, surface area $75 \mathrm{~m}^{2} \mathrm{~g}^{-1}$ ) were mixed with ethylcelulose-N7 (Hercules) binder, anhydrous terpineol (Aldrich) solvent and dispersant using a magnetic stirrer to form a homogeneous paste. The paste was milled in a triple roll mill to break up small agglomerates. The ScSZ scaffold ink was tape cast onto an $8 \mathrm{~mol} \%$ YSZ substrate (fuelcellmaterials YSZ-2.0, $20 \mathrm{~mm}$ in diameter and $0.28 \mathrm{~mm}$ in thickness). The cast scaffolds were dried at $70^{\circ} \mathrm{C}$ for 24 hours, heated at $1{ }^{\circ} \mathrm{C}$ $\mathrm{min}^{-1}$ to $500^{\circ} \mathrm{C}$ and held for two hours to burn off the carbon black and then heated at $3^{\circ} \mathrm{C} \mathrm{min}{ }^{-1}$ to $1250^{\circ} \mathrm{C}$ for a two-hour sintering. The sintered ScSZ scaffolds were then impregnated with $2 \mathrm{M}$ nickel (II) nitrate solution in ethanol. $2 \mu \mathrm{L}$ nitrate solution was infiltrated at each impregnation cycle and the nitrate solution was decomposed at $550^{\circ} \mathrm{C}$ for 1 hour. Each cell underwent 12 impregnation cycles till the nickel loading reached approximately $40 \mathrm{wt} \%$ in the electrode as deduced from the increase in weight after reduction. The average thickness of a scaffold was $10 \mu \mathrm{m}$ as determined from SEM measurements on specimen cross sections and its diameter $14 \mathrm{~mm}$.

Symmetrical cells with Ni-impregnated ScSZ electrodes and YSZ electrolyte fabricated via the route described above were loaded into an electrochemical test station for electrochemical impedance measurements at $650^{\circ} \mathrm{C}, 800^{\circ} \mathrm{C}$ or $950^{\circ} \mathrm{C}$ under open circuit conditions. The test rig is shown schematically in Figure 1. The body of the cell housing (gray in the figure) is made from pyrophyllite machinable ceramic and consists of two parts that are compressively spring-loaded to clamp the cell between the current collector grids. The lower part of the housing receives fuel gas through a central circular aperture and then distributes it to the outer circumference of the housing through a lateral channel. To reach the cell electrodes the fuel diffuses through the annular gap (approximately $10 \mathrm{~mm}$ wide) between the two parts of the housing. The symmetrical cells were heated up in a protective nitrogen atmosphere to the test temperature and then reduced in-situ in the test atmosphere of humidified 5 vol\% hydrogen and $95 \mathrm{vol} \%$ nitrogen at a flow rate of $100 \mathrm{ml} \mathrm{min}{ }^{-1}$ unless specified otherwise. Water vapor was introduced into the gas flow by bubbling the gas supply through deionized water at room temperature. A $0.02 \mathrm{~V}$ sinusoidal voltage was applied in the two electrode measurement set-up over the frequency range $10 \mathrm{MHz}$ to $0.1 \mathrm{~Hz}$. Current collection was made using Pt grids with 100 mesh size (aperture $149 \mu \mathrm{m}$ ) made from wire of $0.076 \mathrm{~mm}$ in diameter unless specified otherwise. The ASR

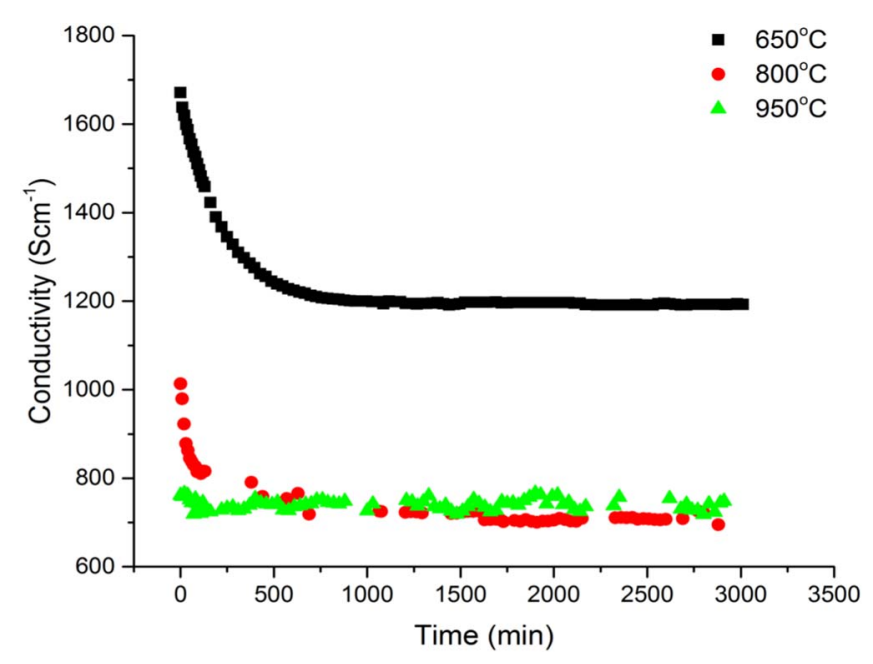

Figure 2. In-plane conductivities of the Ni-impregnated $\mathrm{ScSZ}$ electrode were measured with time as the electrodes were being annealed.

was obtained by multiplying half the measured resistance by the area (circle $14 \mathrm{~mm}$ in diameter) of a single electrode.

Van der Pauw sheet resistance for the electrode was also measured as a function of exposure time. Symmetrical cells were exposed to wet $5 \mathrm{vol} \%$ hydrogen and $95 \mathrm{vol} \%$ nitrogen at a flow rate of $100 \mathrm{ml} \mathrm{min}-1$ for 10 minutes at the test temperature to reduce nickel oxide to nickel and was subsequently cooled at $5 \circ \mathrm{C} \mathrm{min}^{-1}$ to room temperature. The cells were placed in the measurement rig with a probe spacing of $6 \mathrm{~mm}$ and heated at a rate of $5^{\circ} \mathrm{C} \mathrm{min}^{-1}$ back to the reduction temperature for van der Pauw measurement. The conductivity of the electrode was calculated using the average measured thickness of $10 \mu \mathrm{m}$ and assuming that the conductivity does not vary through the thickness.

Microstructures of the Ni-ScSZ anode were examined by secondary electron images using a LEO Gemini 1525 Field Emission Gun Scanning Electron Microscope (FEG-SEM) and Focused Ion Beam-SEM (FIB-SEM) slice-and-view cross-sectional imaging using Zeiss Auriga Cross Beam. The images were processed by Matlab to measure the particle size distributions of nickel in the electrode.

The electrochemical impedance spectra (EIS) were analyzed by equivalent circuit fitting using ZView with R-CPE components.

\section{Results and Discussion}

Electrode electronic conductivity.-The van der Pauw conductivity measurement at elevated temperatures in Figure 2 revealed a rapid initial decrease in the Ni-impregnated ScSZ electrode in-plane conductivity before reaching a steady value. Jung et al. ${ }^{31}$ have shown that application of the van der Pauw method to electrodes impregnated with copper nitrate can be potentially unreliable due to the formation of a copper-rich surface layer during drying. This can produce a high conductivity surface layer on the electrode after reduction which distorts the measured apparent conductivity of the full depth of the electrode. This possibility should be borne in mind with the present results. However, the microstructures presented later show no evidence of such a surface layer, so it is likely that the present results are not influenced by such a layer.

At $650^{\circ} \mathrm{C}$, the in-plane conductivity of the electrode decreased from $1670 \mathrm{~S} \mathrm{~cm}^{-1}$ to $1200 \mathrm{~S} \mathrm{~cm}^{-1}$ within the first $1000 \mathrm{~min}$ of annealing, reaching a plateau of $1200 \mathrm{~S} \mathrm{~cm}^{-1}$ afterwards. The rapid conductivity decrease in the first $1000 \mathrm{~min}$ of annealing was also observed in the electrode annealed at $800^{\circ} \mathrm{C}$, for which the conductivity decreased from $1010 \mathrm{~S} \mathrm{~cm}^{-1}$ to $700 \mathrm{~S} \mathrm{~cm}^{-1}$. At $950^{\circ} \mathrm{C}$, the conductivity remained relatively constant at $750 \mathrm{~S} \mathrm{~cm}^{-1}$ throughout the 3000 min of annealing. The absence of an initial conductivity drop in this case was probably due to the heat-treatment prior to the measurement. Any rapid initial degradation probably happened during 
the slow cooling and heating before the van der Pauw measurement. Different reduction temperatures may result in different nickel distribution and morphology in the electrode. This may lead to the plateau conductivity at $950^{\circ} \mathrm{C}$ being comparable to the conductivity measured at $800^{\circ} \mathrm{C}$.

The conductivities of nickel, ScSZ and YSZ vary with temperature $\mathrm{T}$ according to the equations below. The conductivity of YSZ pellet is measured from a symmetrical cell with platinum electrode in air. ${ }^{32,33}$

$$
\begin{gathered}
\sigma_{S c S Z}(T)=0.46 \cdot\left[6.5 \cdot 10^{2} \exp \left(-\frac{9250}{T}\right)\right]\left[\mathrm{S} \mathrm{cm}^{-1}\right] \\
\sigma_{Y S Z}(T)=\frac{4.55 \cdot 10^{5}}{T} \exp \left(\frac{-10220}{T}\right)\left[\mathrm{S} \mathrm{cm}^{-1}\right] \\
\sigma_{N i}(T)=\frac{1.47 \cdot 10^{5}}{[1+0.0069(T-298)]}\left[\mathrm{S} \mathrm{cm}^{-1}\right]
\end{gathered}
$$

At the annealing temperatures, the conductivity of nickel is $10^{6}$ to $10^{7}$ times the conductivity of ScSZ. In the 4-point probe arrangement, the current flow could possibly extend into the YSZ substrate at elevated temperatures as the ionic conductivity of YSZ is high and the electrode is more than 10 times thinner than the electrolyte. However, even with the increased conductivity at high temperatures, the substrate resistance is estimated to be five to six orders of magnitude higher than that of the Ni-ScSZ electrode. The contribution from the substrate is hence negligible and the measurements represent the true conductivities of the electrodes, averaged over the depth of the electrode. From Equation 3 the conductivity of nickel at $800^{\circ} \mathrm{C}$ is $2.3 \times 10^{4} \mathrm{~S} \mathrm{~cm}^{-1}$ whereas the long term steady conductivity of the sample aged at $800^{\circ} \mathrm{C}$ is approximately $700 \mathrm{~S} \mathrm{~cm}^{-1}$. This is only $3 \%$ of the bulk value and indicates that the nickel network is not wellconnected despite its high volume fraction and favorable location on the internal surfaces of the porous zirconia scaffold. The rapid initial reduction in conductivity is therefore likely to reflect the microstructural change of the nickel within the electrode over time. Klemens $\varnothing$ et al. ${ }^{23}$ also observed a severe initial degradation for nickel impregnated YSZ anode at $650^{\circ} \mathrm{C}$, though on a time-scale of $24 \mathrm{~h}$, and attributed the degradation to nickel sintering by surface diffusion.

Electrochemical impedance spectroscopy.-Three capacitive processes were observed at $650^{\circ} \mathrm{C}$ in addition to the ohmic series resistance as shown in Figure 3. The small capacitive process at high frequency was assigned to the transfer of oxygen ions across the inter-
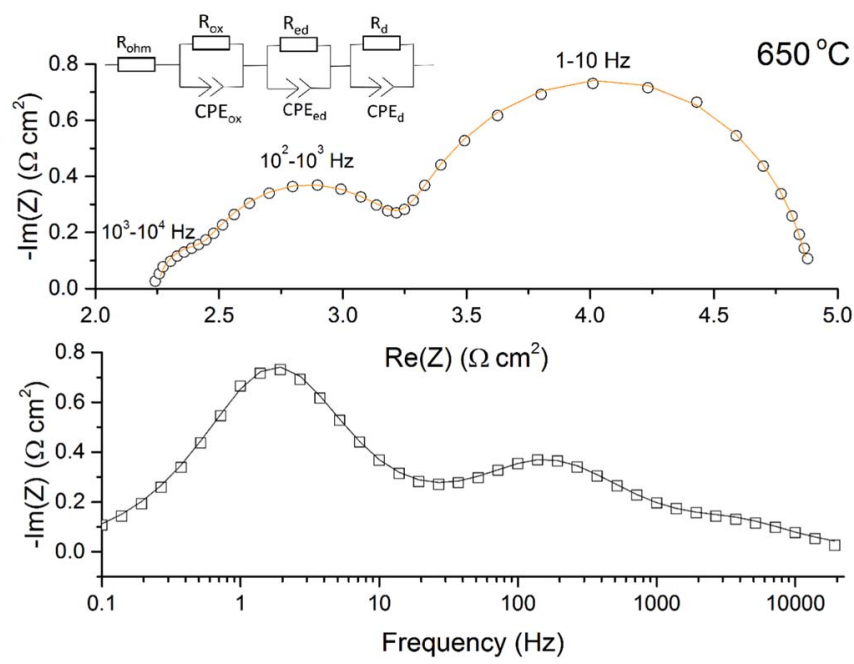

Figure 3. Nyquist plot and Bode plot for a symmetrical cell aged at $650^{\circ} \mathrm{C}$ for $30 \mathrm{~min}$. The dots represent the experimental data and the solid lines represent the equivalent circuit fitting. The equivalent circuit model is shown in the inset.

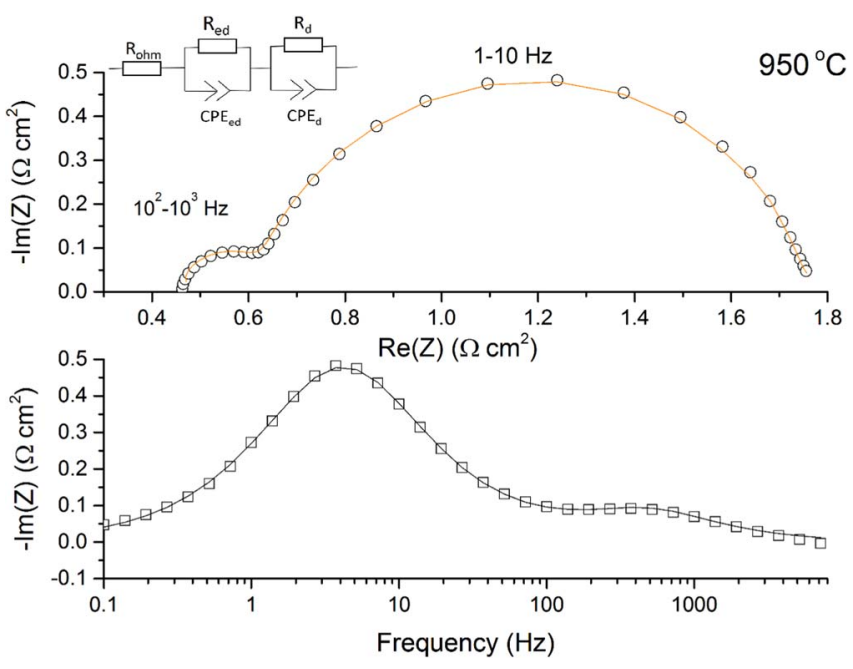

Figure 4. Nyquist plot and Bode plot for a symmetrical cell aged at $950^{\circ} \mathrm{C}$ for $70 \mathrm{~min}$.

face between the YSZ electrolyte and the ScSZ electrode..$^{32,34,35}$ The process at $10^{2}-10^{3} \mathrm{~Hz}$ was assigned to the electrochemical anodic reaction. ${ }^{36-39}$ The large low frequency response at $1-10 \mathrm{~Hz}$ is most likely a gas conversion impedance due to the test rig geometry, and is caused by diffusion of gas molecules from the flowing gas stream into, and out of, the electrode compartments of the cell test chamber. ${ }^{40,41}$ The different contributions are shown as an equivalent circuit model in the inset and their assignments are discussed later.

When the annealing temperature was increased to $800^{\circ} \mathrm{C}$ or $950^{\circ} \mathrm{C}$, the oxygen transfer resistance could not be distinguished in the impedance spectra as shown in Figure 4. The medium frequency contribution assigned to the electrochemical reaction became much smaller and the low frequency diffusion contribution was dominant.

The following section describes the variation of ohmic resistance, anodic reaction resistance and diffusion resistance with time as the electrodes were aged at the different test temperatures.

Figure 5 shows the time evolution of the ASR from the different contributions at the isothermal annealing temperature of $650^{\circ} \mathrm{C}, 800^{\circ} \mathrm{C}$ and $950^{\circ} \mathrm{C}$. Note that for $800^{\circ} \mathrm{C}$ and $950^{\circ} \mathrm{C}$ the transfer resistance contribution is included in the ohmic series resistance as it cannot be distinguished as a separate component. All the contributions tend to show an initial increase over the first $1000 \mathrm{~min}$ of annealing, followed

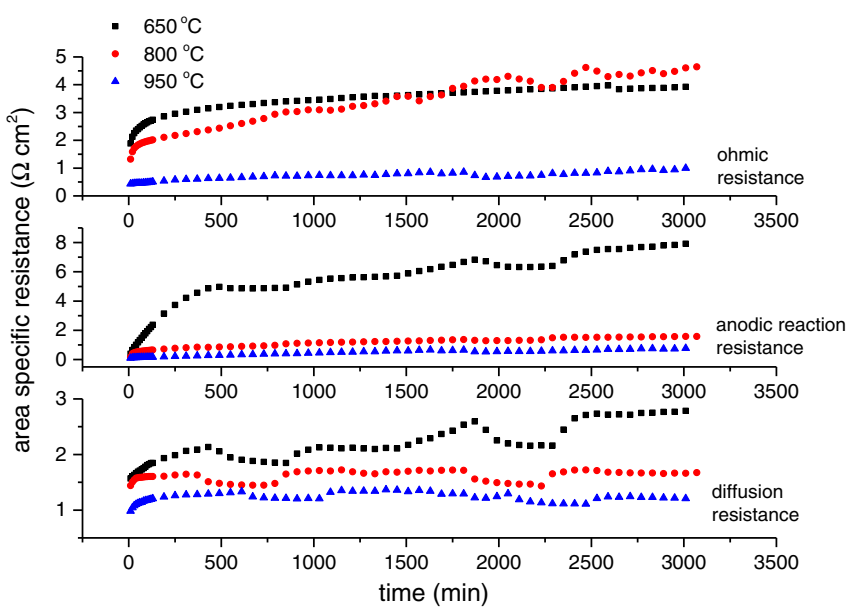

Figure 5. The area specific resistance contributions as a function of time at different annealing temperatures. The measurement was made at $10 \mathrm{~min}$ intervals during the first $120 \mathrm{~min}$ and then at $60 \mathrm{~min}$ interval thereafter. 


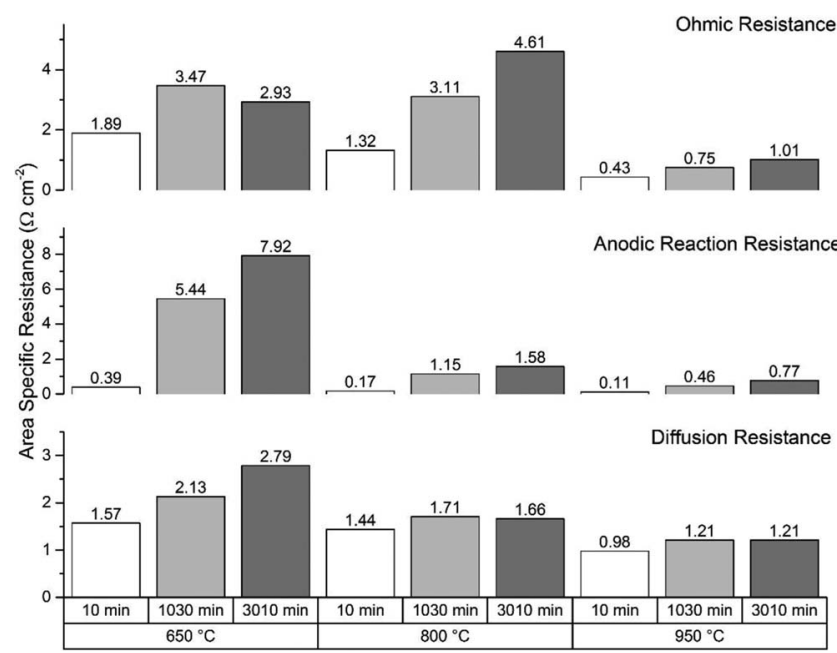

Figure 6. ohmic resistance, anodic reaction resistance and diffusion resistance of the electrode at $10 \mathrm{~min}, 1030 \mathrm{~min}$ and $3010 \mathrm{~min}$ of annealing.

by a more gradual increase at longer times. Figure 6 summarizes the change in ASR contributions in the two stages.

The ASR evolution for the diffusion contribution in Figure 5 exhibits a periodic fluctuation, which is seen to a lesser degree in the anodic reaction contribution. These fluctuations were found to be due to variation from $3.0 \%$ to $3.7 \%$ in the water content of the inlet gas caused by changes in room temperature $\left(24^{\circ} \mathrm{C}\right.$ to $\left.28^{\circ} \mathrm{C}\right)$. As discussed later, these fluctuations are consistent with the influence of water vapor pressure on the individual contributions to the ASR in the model used to interpret the data.

It is interesting that all three contributions to the ASR show a similar qualitative evolution, which is particularly unexpected for the ohmic contribution. Furthermore, the magnitude of the ohmic contribution is significantly greater than expected from the electrolyte pellet. (The ASR plotted in the figure is for unit area of a single electrode and therefore has a contribution from half the thickness the electrolyte pellet.) For example, at $800^{\circ} \mathrm{C}$ the measured initial ohmic ASR is 1.32 $\mathrm{ohm} \mathrm{cm}^{2}$ whereas that expected from the YSZ electrolyte pellet (using Equation 2) is $0.45 \mathrm{ohm} \mathrm{cm}$. This suggests that there was a problem with current collection from the electrode to the platinum grids that became worse as the in-plane resistance of the electrode decreased, as shown in Figure 2. Such an in-plane resistance can reduce the active area of the electrode as the electrode conductivity decreases and therefore influences all the contributions to the ASR. However, in this case, the measured lateral conductivity of the electrodes is sufficiently high that transfer of electrons to the platinum grid wires should not be a problem for the grid size used. This probably indicates that the current collector grids were not making good uniform contact on the electrode surface so that the current collection points were separated by larger distances than the grid aperture size. An alternative explanation is that the measured lateral conductivity of the electrode is dominated by a nickel-rich surface layer and the through-thickness conductivity of the electrode is poor and degrades with time. However this is not supported by the observed nickel distribution in the electrodes that is described later.

In order to demonstrate the influence of lateral current collection, similar symmetrical cells were fabricated with a layer of silver paint applied on top of the electrode before inserting in the test rig in order to improve current collection. Electrochemical impedance measurements were then carried out at $650^{\circ} \mathrm{C}$ in both $5 \mathrm{vol} \% \mathrm{H}_{2}$ and $95 \mathrm{vol} \%$ $\mathrm{H}_{2}$. The evolution of the ASR contributions for these cells is presented in Figure 7. These results show that the ohmic component is now much more stable (Figure 8). Nevertheless, there is still some residual increase with time over the initial $1030 \mathrm{~min}$ which could indicate a small contribution from the through thickness electronic conduction in the electrode. In contrast, the anodic reaction contribu-

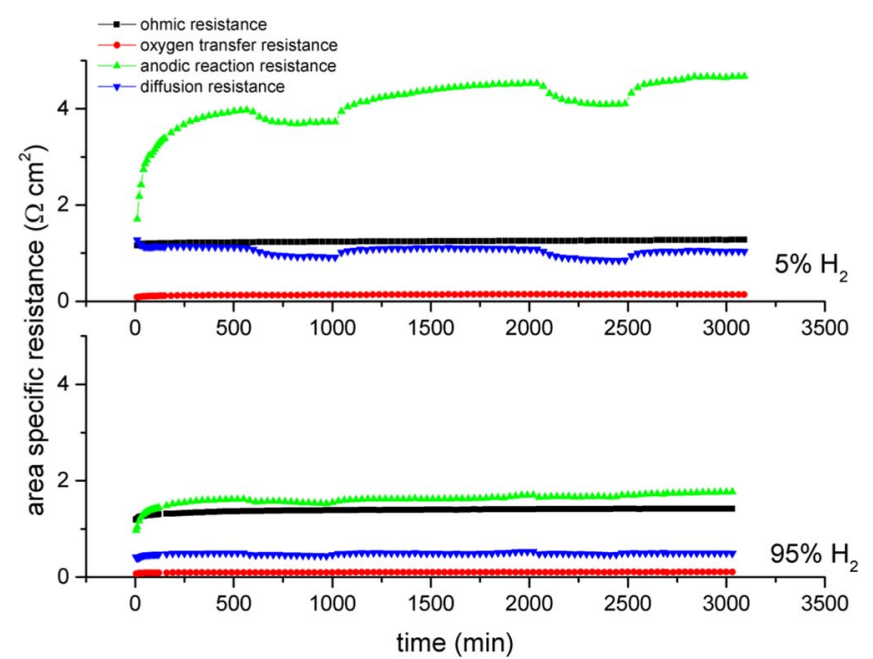

Figure 7. The time evolution of the contributions to ASR from the ohmic, oxygen ion transfer, anodic reaction and the gas diffusion processes. Measurement was made at $650^{\circ} \mathrm{C}$ in two gas compositions 1) humidified $5 \% \mathrm{H}_{2}$ and $95 \% \mathrm{~N}_{2}$ (above), 2) humidified $95 \% \mathrm{H}_{2}$ and $5 \% \mathrm{~N}_{2}$ (below), with a flow rate of $100 \mathrm{ml} \mathrm{min}^{-1}$. Silver paint was applied onto the surface of the electrodes in addition to the Pt mesh contact to improve current collection.

tion still displays a marked increase with time, indicating its inherent sensitivity to microstructure changes in the electrode. The diffusion and electrochemical reaction contributions again show the periodic fluctuations caused by humidity changes. The diffusion contribution shows no increasing trend with time, but is reduced considerably by an increase in hydrogen partial pressure. Although the anodic reaction resistance also decreases with increase in hydrogen concentration, it still demonstrated an initial stage of rapid increase with exposure time. Figure 8 summarizes the values for the three resistances at the end of 1030 minutes and 3010 minutes of annealing and again illustrates the relatively small change in ohmic and diffusion resistances as compared to the change in anodic reaction resistance. Nickel coarsening brings about two degradation effects: i) a loss in nickel percolation, and ii) a reduction in triple phase boundary length. The ASR data in Figure 7 hence confirm that the increase in ohmic and diffusion resistance seen in Figure 5, is a result of percolation (conductivity) loss while the increase in anodic reaction resistance seen in both figures

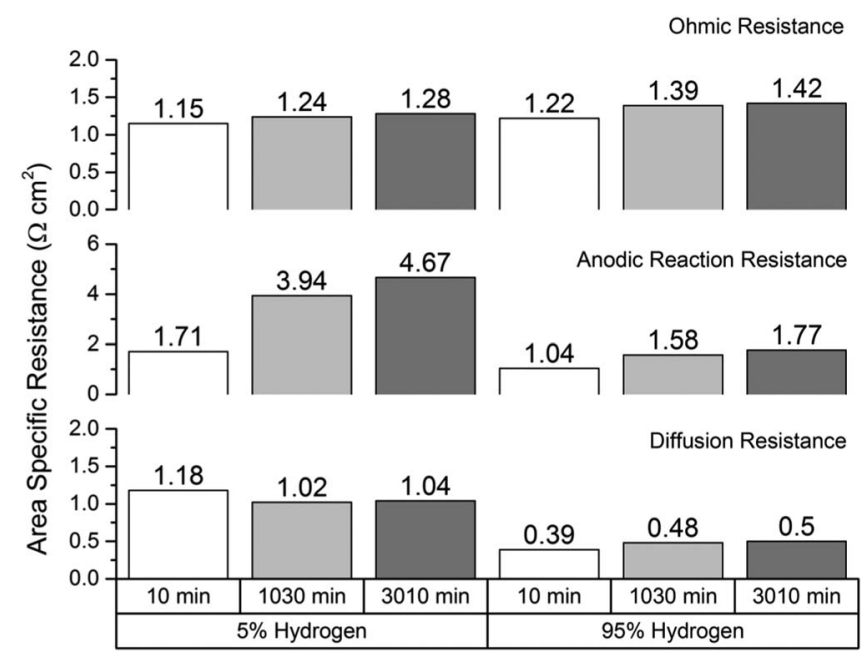

Figure 8. Values of the three contributions to the ASR at $10 \mathrm{~min}, 1030 \mathrm{~min}$ and $3010 \mathrm{~min}$ at $650^{\circ} \mathrm{C}$ with a silver paint coating on the cell to improve current collection. 


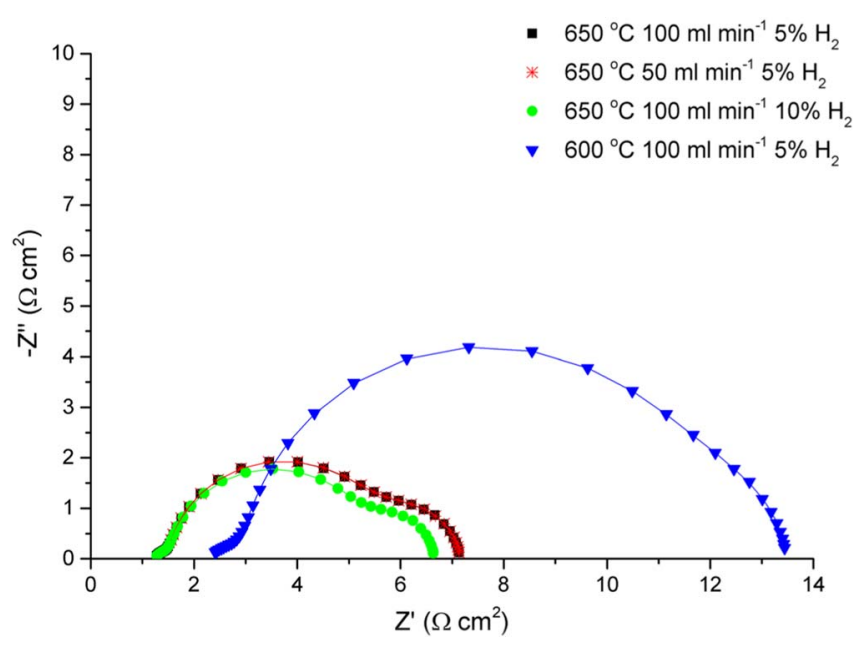

Figure 9. Nyquist plots for a symmetrical cell, with silver paint current collection, measured at different temperatures, fuel gas composition and gas flow rate (indicated in the legend).

is caused by loss of both percolation and TPB density, i.e. a loss of active TPB density.

Increasing the hydrogen molar fraction from 5\% to $95 \%$ reduced both the anodic reaction resistance and the diffusion resistance by a factor of approximately 2 (see Figure 8 and Figure 9), confirming that these two contributions are dependent on gas composition.

In order to support the identification of the different contributions to the ASR, experiments were carried out, on electrodes with silver paste as additional current collector, in which flow rate, temperature and hydrogen concentration were changed. In the following example the specimen had been annealed for $3010 \mathrm{~min}$ at $650^{\circ} \mathrm{C}$ in an atmosphere of humidified $5 \% \mathrm{H}_{2}$ and $95 \% \mathrm{~N}_{2}$ before the impedance measurement to reduce the complicating effects of time dependent changes on the cell performance. The results are shown in Figure 9.

Decreasing the flow rate of the fuel gas from $100 \mathrm{ml} \mathrm{min}^{-1}$ to 50 $\mathrm{ml} \mathrm{min}{ }^{-1}$ had no detectable influence on any of the contributions to the ASR. Due to the test rig configuration shown in Figure 1, changes to gas mass transport outside the test housing are not expected to influence conditions inside the housing because of the relatively long diffusion path between the two parts of the housing. Increasing the hydrogen content from $5 \mathrm{vol} \%$ to $10 \mathrm{vol} \%$ in the gas supply decreased both the medium frequency and low frequency contributions. The anodic electrochemical reaction resistance at medium frequencies decreased because a higher hydrogen activity is available at the triple phase boundary reaction sites. Similarly, a higher hydrogen molar fraction in the gas outside the housing provides a greater driving force for diffusion into the cell chamber. When the measurement temperature was decreased from $650^{\circ} \mathrm{C}$ to $600^{\circ} \mathrm{C}$, all four resistance values increased, but especially the medium frequency contribution assigned to the electrochemical reaction.

Microstructure characterization.-The microstructure of the nickel-impregnated ScSZ electrode was examined before and after isothermal annealing. The morphology of the nickel and ScSZ phases are identified from the SEM images.

The microstructure observations revealed that the ScSZ after sintering formed an interconnecting porous scaffold as shown in Figure 10a). After infiltration and reduction the nickel particles were homogeneously distributed onto the $\mathrm{ScSZ}$ surface as nanometer-size spheres facing the open pores (Figure 10b). The thickness of the scaffold is approximately $10 \mu \mathrm{m}$ and the nickel particles are distributed throughout the whole scaffold as shown in Figure 10c).

The FIB-SEM image in Figure 11 confirmed that nickel particles were distributed over the entire ScSZ porous backbone. There is no indication of a nickel-rich surface region that would have distorted the a)

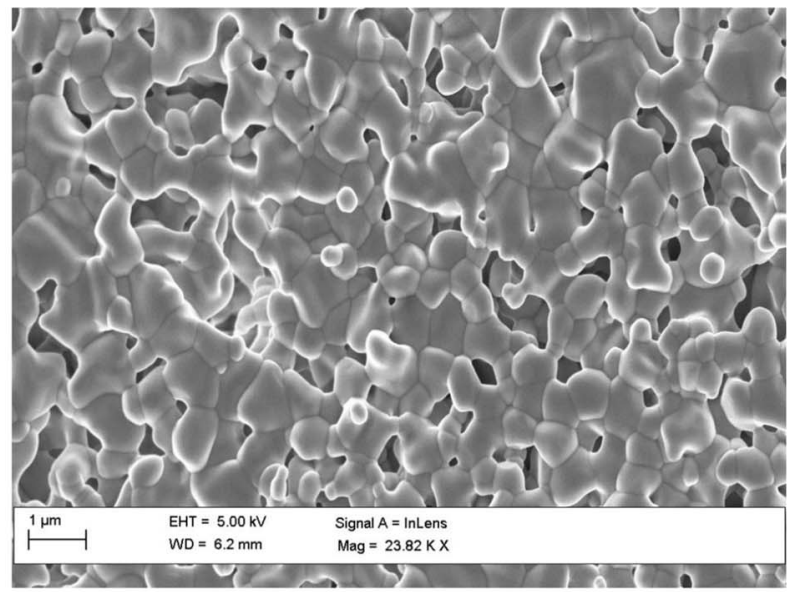

b)

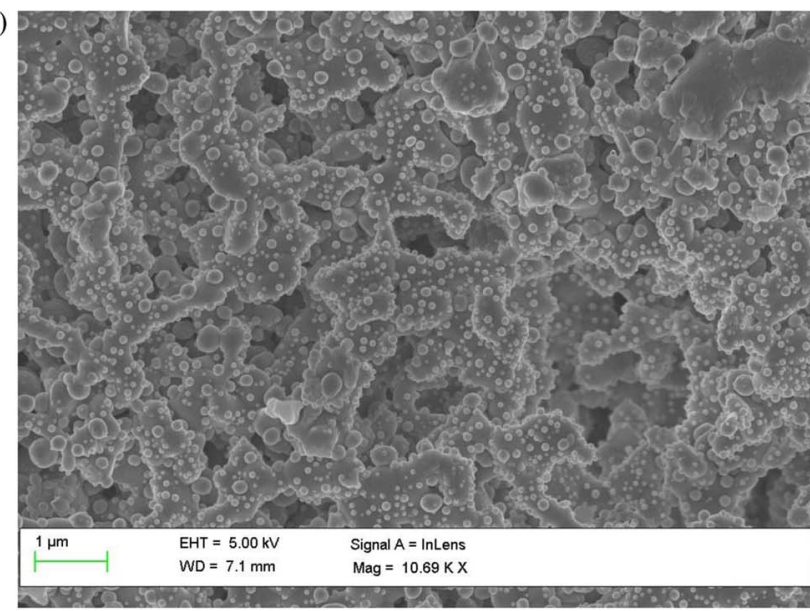

c)

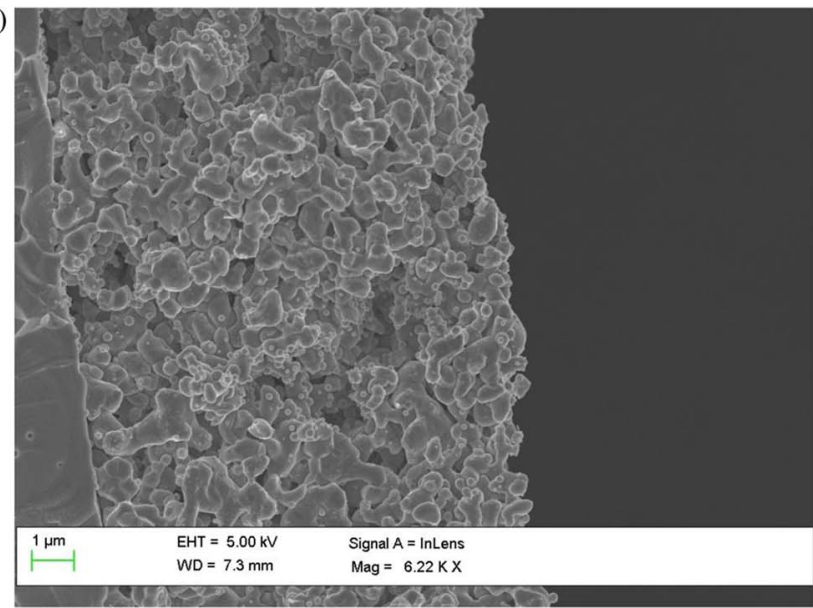

Figure 10. SEM micrographs of a) the ScSZ porous scaffold after sintering, b) the ScSZ scaffold after impregnating with nickel, c) the cross section of nickel-ScSZ electrode after being reduced at $950^{\circ} \mathrm{C}$ and held for $3010 \mathrm{~min}$.

conductivity measurements. The ScSZ grains are generally faceted whereas the nickel particles are spheroidal. This distinctive morphological difference between the two phases enables the identification of nickel particles from the secondary electron images. The microstructures of the electrodes aged for $30 \mathrm{~min}$ and for $3010 \mathrm{~min}$ are compared in Figure 12.

As shown in Figure $12 \mathrm{a} 2$ and $12 \mathrm{~b} 2$, the circular nickel particles were identified and the radii of the circles measured using Matlab. The particle size distributions of nickel at the beginning (30 min) of annealing and the end $(3010 \mathrm{~min})$ are presented in Figure 13 . The 


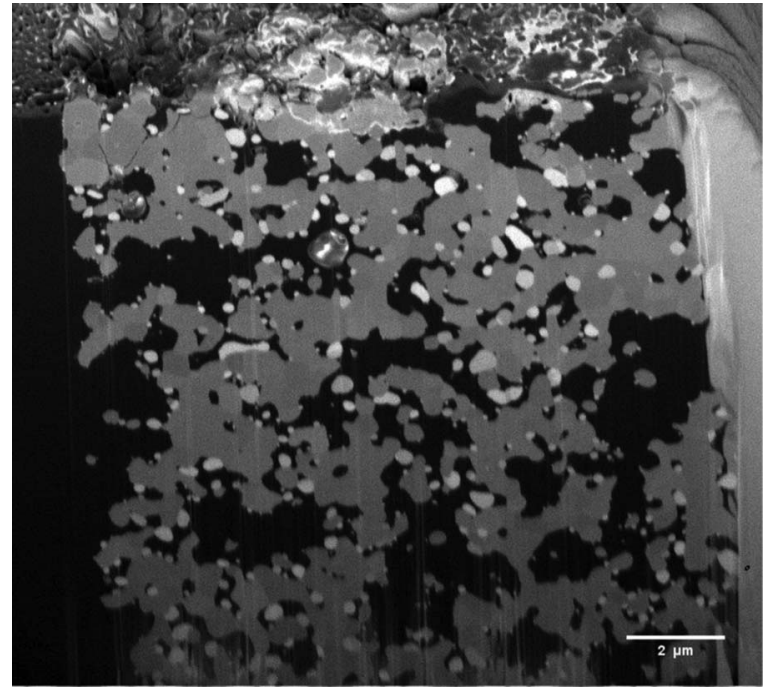

Figure 11. The secondary electron cross-sectional image of the image sliced and polished by focused ion beam shows three different phases with different color contrast. The darkest phase is the epoxy resin that fills the pores. The brightest phase is nickel, which appears as nearly spherical particles. The gray phase in-between is ScSZ, forming a support network. The electrode has been reduced and aged at $950^{\circ} \mathrm{C}$ in wet $5 \%$ hydrogen and $95 \%$ nitrogen for $30 \mathrm{~min}$.

frequency is weighted by the diameter of the particle, so that the frequency distribution can be directly related to the TPB length.

An increase in particle size with the annealing time is clearly evident in Figure 13. The fine nickel particles with a particle size less than $40 \mathrm{~nm}$ disappeared after $3010 \mathrm{~min}$ of ageing and some particles grew to above $200 \mathrm{~nm}$ in diameter. The number of spherical particle detected decreased from 850 at $10 \mathrm{~min}$ to 294 at $3010 \mathrm{~min}$ while the total volume of the spheres were conserved. The particle size

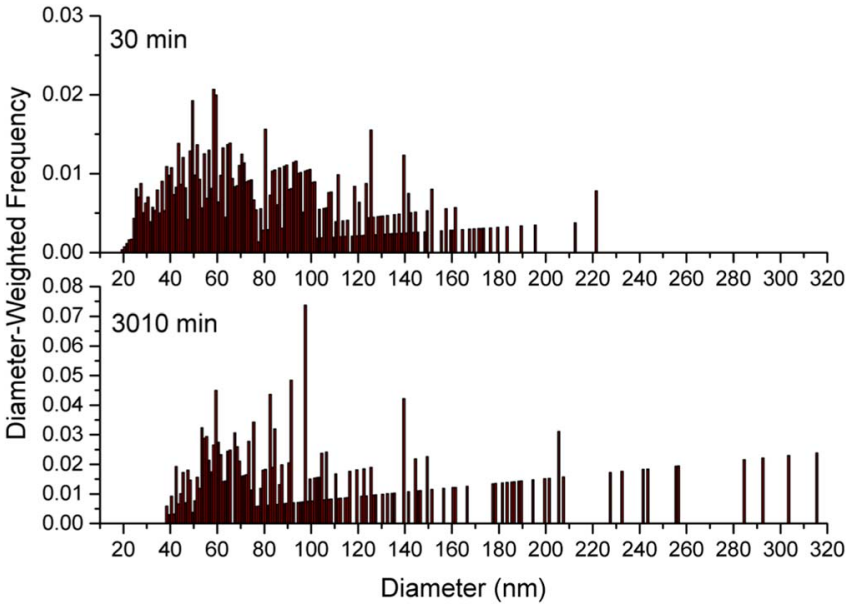

Figure 13. The diameter-weighted particle size distributions of nickel in the electrode after $30 \mathrm{~min}$ (above) and $3010 \mathrm{~min}$ (below) of annealing.

distribution indicated both an increase in average particle size and a decrease in the number of particles.

Physical model of electrode ASR.-The 1D distributed model developed by Bertei et al. ${ }^{32}$ was used to interpret the degradation in the nickel impregnated ScSZ electrode semi-quantitatively. The model treats the electrode microstructure as a continuum with a key parameter being the effective TPB length per unit volume of the electrode. Other microstructure parameters in the model that influence the contribution from the electrochemical reaction to a lesser degree are the area of the $\mathrm{Ni} / \mathrm{ScSZ}$ interface per unit volume, the conductivity factor for the ionic conducting network (defined as the conductivity of the network compared with the conductivity of the dense ionic conductor) and the electrode thickness. The degradation due to nickel coarsening a1)

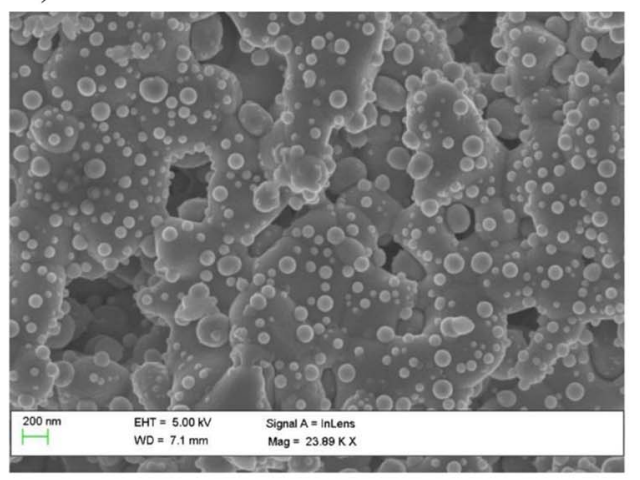

a2)

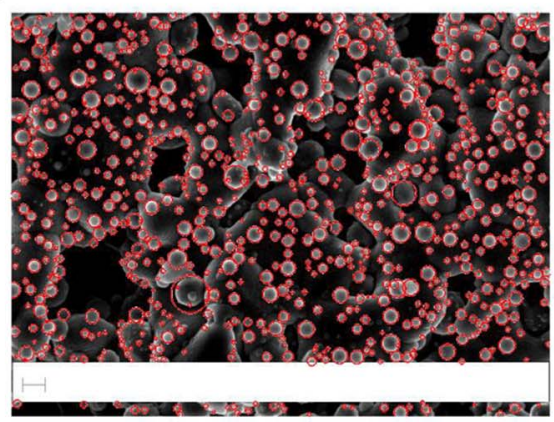

b1)

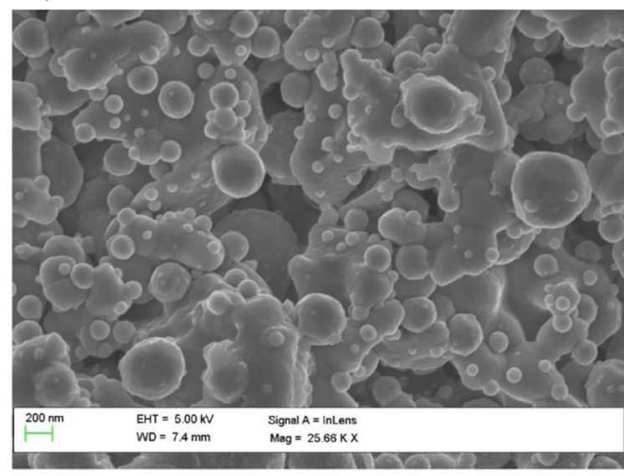

b2)

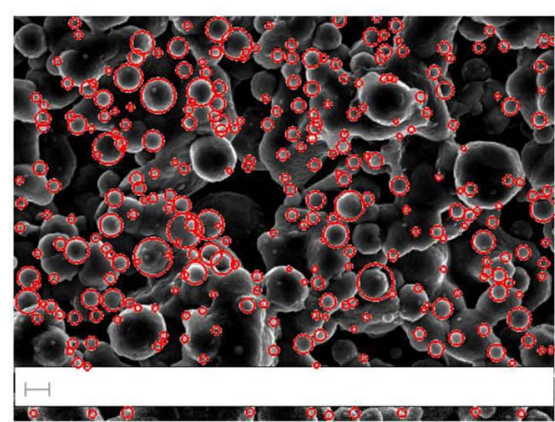

Figure 12. Secondary electron images of an electrode reduced and aged at $950^{\circ} \mathrm{C}$ for $30 \mathrm{~min}$ a1) and $3010 \mathrm{~min}$ b1). The images were processed for image analysis by enhancing the contrast and edge threshold level to emphasize the circular objects (nickel particles) in a2) and b2). 


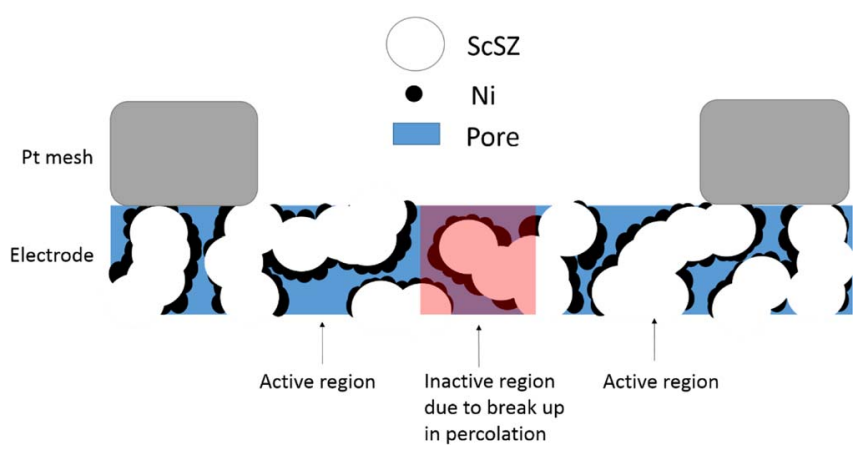

Figure 14. Schematic of the electrode microstructure between two Pt mesh contact points (no additional silver current collection) showing the inactive regions due to break up in percolation of the nickel network upon degradation (note: figure not drawn to scale).Anodic reaction takes place at the percolating triple phase boundaries and the electrons released from hydrogen oxidation flow along the nickel path (in black) to the Pt mesh current collector.

can be quantified by two time-dependent parameters: 1) decreasing active anode area due to increasing electronic current collection resistance; and 2) decreasing active TPB density.

The model makes the following simplifying assumptions.

i. the effective electronic conductivity is much larger than the effective ionic conductivity in the electrode;

ii. within the active area, the microstructural properties are uniform; iii. the anodic reaction obeys Butler-Volmer kinetics.

Figure 14 illustrates the contact, in the absence of silver coating, between the electrode and the Pt mesh current collector, and also the area of the electrode between two contact points. The inactive region, in which the nickel connection toward the neighboring current collector is cut off, enlarges as nickel coarsening breaks up the percolation.

The impedance spectra obtained during annealing of the specimens without the silver current collection were analyzed according to the following steps.

1) The oxygen transfer resistance was determined (using parameter values established previously for a similar ScSZ scaffold ${ }^{32}$ ) and compared with the experimental data to decouple it from the ohmic series resistance. At $650^{\circ} \mathrm{C}$ the initial ASR contribution from oxygen transfer was measured to be $0.13 \mathrm{ohm} \mathrm{cm}^{2}$ in the present experiments, in good agreement with the value of 0.14 $\mathrm{ohm} \mathrm{cm}^{2}$ from the model parameters. At the higher temperatures (at which this contribution could not be separated experimentally) the model predictions are $0.009 \mathrm{ohm} \mathrm{cm}^{2}$ at $800^{\circ} \mathrm{C}$ and $0.0012 \mathrm{ohm} \mathrm{cm}^{2}$ at $900^{\circ} \mathrm{C}$. Therefore at these temperatures this contribution is negligible and the ohmic resistance is dominated by the electrolyte and current collection resistances.

2) The measured ohmic resistance was then compared with the initial ohmic resistance to calculate the time-dependent active area fraction assuming in all cases that the initial active area fraction is $100 \%$. The result is shown in Figure 15 indicating that the active area fraction exhibited a rapid decrease over the first $1000 \mathrm{~min}$ of annealing and then slowed down afterwards.

3) Measurements of room temperature changes during the annealing were used to determine the water vapor pressure variation with time, assuming equilibrium in the water bubbler. Using this, the periodic fluctuation in the anodic reaction resistance due to water molar change was corrected to a common water vapor concentration of $3 \%$ assuming that the exchange current density is proportional to $y_{\mathrm{H}_{2} \mathrm{O}}^{0.52}$ where $y$ indicates mole fraction as specified for the exchange current density in the model..$^{42}$ The variation in percolating TPB density was thus separated from the variation in active area fraction as shown in Figure 16. The TPB density was then estimated from the model using the values for the exchange current density per unit length of TPB and the effective ionic

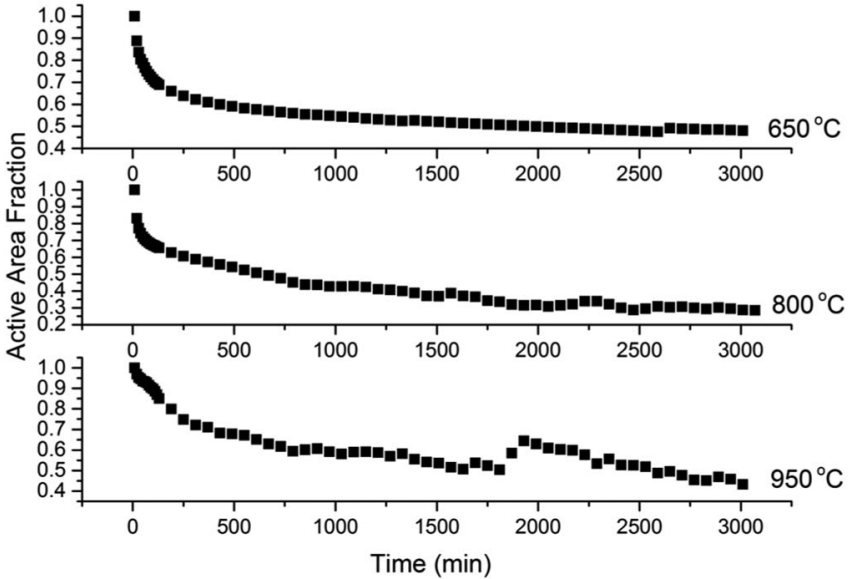

Figure 15. The time evolution of active area fraction of electrodes at $650^{\circ} \mathrm{C}$, $800^{\circ} \mathrm{C}$ and $950^{\circ} \mathrm{C}$

conductivity of ScSZ at each temperature, as established previously when applying the model to similar Ni-infiltrated ScSZ electrodes. ${ }^{32}$

The TPB densities in Figure 16 showed a sharp decrease over the first 1000 min of annealing. A plateau was reached after the initial degradation. At $950^{\circ} \mathrm{C}$ and $650^{\circ} \mathrm{C}$, the plateau TPB density was approximately $1.8 \times 10^{12} \mathrm{~m} \mathrm{~m}^{-3}$ and $1.2 \times 10^{12} \mathrm{~m} \mathrm{~m}^{-3}$ respectively. However, there is not a smooth trend with annealing temperature. Surprisingly, the highest plateau density of $5.5 \times 10^{12} \mathrm{~m} \mathrm{~m}^{-3}$ was found at $800^{\circ} \mathrm{C}$. (Although the TPB density is higher at 800 than $950^{\circ} \mathrm{C}$, the ASR for the electrochemical reaction is lower at $950^{\circ} \mathrm{C}$ because of the temperature dependence of the anodic reaction.) This is believed to be due to the different reduction temperatures giving different initial nickel microstructures that also evolve differently. The initial TPB densities of the nickel-impregnated electrodes are similar in magnitude to the TPB densities measured by FIB-SEM tomography in Ni-impregnated gadolinium-doped ceria scaffold electrodes. ${ }^{28}$

For the experiments in which a silver paste current collector was used, the effective area fraction was assumed to be 1, independent of ageing time since the effect of percolation breakup is mitigated. The expected anodic reaction resistance at different annealing stages with the silver current collector were predicted by assuming the same evolution of TPB density shown in Figure 16 at $650^{\circ} \mathrm{C}$ with 5 vol\% hydrogen. The predicted values are compared with the measured

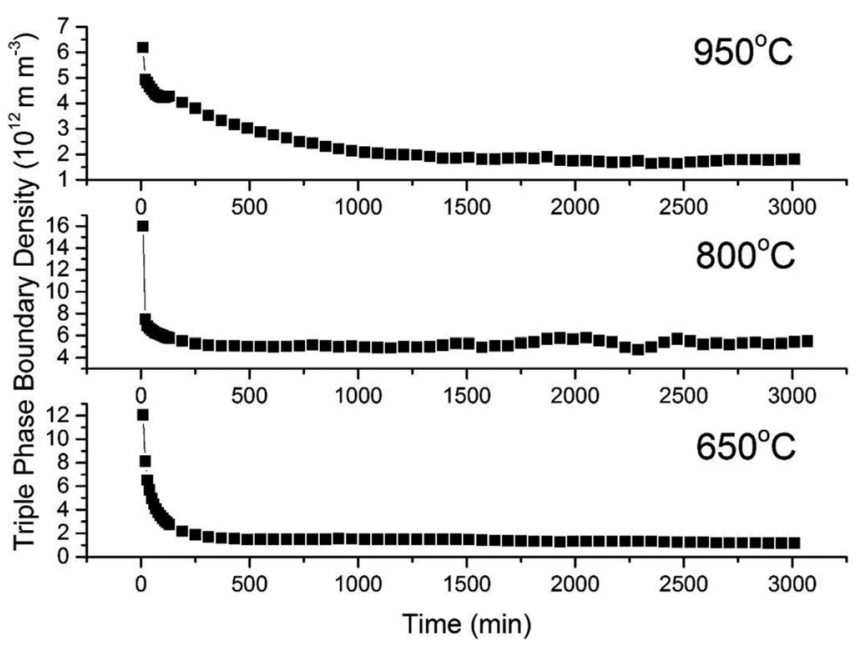

Figure 16. The evolution of triple phase boundary densities with annealing time at $950^{\circ} \mathrm{C}, 800^{\circ} \mathrm{C}$ and $650^{\circ} \mathrm{C}$. 
Table I. Comparison between the model predicted ASR and the measured ASR at $650^{\circ} \mathrm{C}$ with silver paste in moist $(3$ vol $\%$ water vapor) 5 vol\% hydrogen and 95 vol\% nitrogen.

\begin{tabular}{lcc} 
& $\begin{array}{c}\text { Predicted } \\
\text { ASR }\left(\Omega \mathrm{cm}^{2}\right)\end{array}$ & $\begin{array}{c}\text { Measured } \\
\text { ASR }\left(\Omega \mathrm{cm}^{2}\right)\end{array}$ \\
\hline Anodic Reaction Resistance at $10 \mathrm{~min}$ & 0.61 & 1.71 \\
Anodic Reaction Resistance at $1030 \mathrm{~min}$ & 3.84 & 3.94 \\
Anodic Reaction Resistance at 3010 min & 4.80 & 4.67
\end{tabular}

values (Figure 7) as shown in Table I. The predicted and measured effects are in reasonable agreement except for the 10 minute data. The discrepancy at this stage is probably due to sensitivity of the early ageing results to reproducibility in reduction procedure and initial heating to test temperature.

Models have also been published to estimate the TPB density of infiltrated electrodes. Reszka et al. ${ }^{43}$ presented a model of the microstructure of infiltrated electrodes that considers the total and active TPB lengths as functions of infiltrated particle size, scaffold porosity and pore size and volume fraction of infiltrate. For the current materials the initial infiltrated particle size is approximately $100 \mathrm{~nm}$, scaffold porosity is $50 \%$, the scaffold particle (grain) size is $0.5 \mu \mathrm{m}$, the scaffold pore size is approximately $1 \mu \mathrm{m}$, and the volume fraction of nickel is $20 \%$. According to their model the active TPB density is not very sensitive to the scaffold pore size and is approximately 0.8 unit $^{-2}$ (where a unit is the infiltrated particle size) for $20 \mathrm{vol} \%$. infiltrate loading. This corresponds to a TPB density of $800 \times 10^{12}$ $\mathrm{m}^{-2}$, which is much greater than the value estimated from the electrochemical model and probably reflects the fact that the model for the infiltrated microstructure is not sufficiently close to reality. Bertei et al. ${ }^{44}$ present a similar model which predicts a connected TPB density equal to approximately $50 d_{\mathrm{s}}{ }^{2}$, (where $d_{\mathrm{s}}$ is the scaffold particle size and is 5 times the infiltrated particle size as in the present experiments) and in the present case corresponds to a connected TPB density of 8 $\times 10^{12} \mathrm{~m}^{-2}$. This latter value is of a similar order of magnitude to the total TPB density of $18 \times 10^{12} \mathrm{~m}^{-2}$ measured by tomography in similar electrodes with a doped ceria scaffold infiltrated by nickel ${ }^{28}$ and the connected TPB densities estimated in the current specimens before the isothermal annealing (Figure 16).

\section{Conclusions}

In this paper, an early rapid degradation in the ASR of nickelimpregnated $\mathrm{ScSZ}$ electrodes was observed and correlated with changes in the electrode microstructure. The in-plane conductivity of the electrodes was also observed to decrease significantly with exposure time. Electrochemical impedance spectroscopy revealed four contributions to the overall ASR of the symmetrical cells: a series resistance from the electrolyte support; a small high frequency contribution from transfer of oxygen ions from the electrode to the electrolyte; a medium frequency contribution from the electrochemical anodic reaction; and a low frequency contribution from gas diffusion into the test chamber. The increase in ohmic resistance revealed an issue with current collection when using platinum mesh current collectors that caused all contributions to increase in a similar way. This showed that disruption of the percolating nickel pathways in the electrodes decreased their effective active area. This was confirmed in experiments in which a silver layer was applied on top of the electrode to improve current collection.

The microstructure images showed that nickel particles coarsened after annealing in wet hydrogen. The degradation due to nickel coarsening was described by two time-dependent parameters, 1) decreasing active anode fraction as a result of percolation break-up and 2) decreasing triple phase boundary density. A previously published physical model was used to extract the active anode fraction and the triple phase boundary densities in the active regions from electrochemical impedance spectra. Both parameters reduced sharply during the ini- tial stage of annealing and then stabilize to reasonably steady values. Decoupling the TPB density from the active anode area fraction verified that the major degradation associated with nickel coarsening in the impregnated electrode takes place at a relatively short time-scale (1000 min) as compared to the desired operational life time of solid oxide fuel cells in most applications $(40,000 \mathrm{~h}$ or more).

\section{Acknowledgment}

This project received funding from Chinese Scholarship CouncilImperial Scholarship and EPSRC through EP/M014045/1 "Electrodes by Design - Microstructural Engineering of High Performance Electrodes for Solid Oxide Fuel Cells" for funding this work. Antonio Bertei acknowledges funding from the European Union's Horizon 2020 research and innovation programme under the Marie Skłodowska-Curie grant agreement No. 654915.

\section{References}

1. A. B. Stambouli and E. Traversa, "Solid oxide fuel cells (SOFCs): a review of an environmentally clean and efficient source of energy," Renew. Sustain. Energy Rev., 6(5), 433 (2002).

2. N. Q. Minh, "Solid oxide fuel cell technology - Features and applications," Solid State Ionics, 174(1-4), 271 (2004).

3. S. . Singhal, "Advances in solid oxide fuel cell technology," Solid State Ionics, 135(1), 305 (2000).

4. R. J. Gorte, S. Park, J. M. Vohs, and C. Wang, "Anodes for Direct Oxidation of Dry Hydrocarbons in a Solid-Oxide Fuel Cell," Adv. Mater., 12(19), 1465 (2000).

5. S. Tao and J. T. S. Irvine, "A redox-stable efficient anode for solid-oxide fuel cells.," Nat. Mater, 2(5), 320 (2003).

6. B. Steele, "Appraisal of $\mathrm{Ce} 1-\mathrm{yGdyO} 2-\mathrm{y} / 2$ electrolytes for IT-SOFC operation at $500^{\circ} \mathrm{C}, "$ Solid State Ionics, 129, 95 (2000).

7. S. E. Veyo, W. L. Lundberg, S. D. Vora, and K. P. Litzinger, "Tubular SOFC Hybrid Power System Status," in ASME Paper No. GT2003-38943, 2003, pp. 1-7.

8. S. C. Singhal, "Science and Technology of Solid-Oxide Fuel Cells," MRS Bull., 25(3), $16(2000)$

9. S. Aruna, M. Muthuraman, and K. Patil, "Synthesis and properties of Ni-YSZ cermet: anode material for solid oxide fuel cells," Solid State Ionics, 111(1-2), 45 (1998).

10. S. H. Clarke, A. L. Dicks, K. Pointon, T. A. Smith, and A. Swann, "Catalytic Aspects of the Steam Reforming of Hydrocarbons in Internal Reforming Fuel Cells," Catal. Today, 38(4), 411 (1997).

11. S. P. Jiang, "Hydrogen Oxidation at the Nickel and Platinum Electrodes on YttriaTetragonal Zirconia Electrolyte," J. Electrochem. Soc., 144(11), 3777 (1997).

12. J. Fergus, R. Hui, X. Li, D. P. Wilkinson, and J. Zhang, Solid Oxide Fuel Cells: Materials Properties and Performance, CRC Press, 2016.

13. M. Okamoto, Y. Akimune, K. Furuya, M. Hatano, M. Yamanaka, and M. Uchiyama, "Phase transition and electrical conductivity of scandia-stabilized zirconia prepared by spark plasma sintering process," Solid State Ionics, 176(7-8), 675 (2005).

14. B. Bai, N. M. Sammes, A. L. Smirnova, and G. Tompsett, "Characterization of Scandia Stabilized Zirconia Doped With Various $\mathrm{Bi}_{2} \mathrm{O}_{3}$ Additions as an Intermediate Temperature Solid Oxide Fuel Cell Electrolyte," J. Fuel Cell Sci. Technol., 7(2), (2010).

15. C. Haering, A. Roosen, H. Schichl, and M. Schnöller, "Degradation of the electrical conductivity in stabilize zirconia system Part II: Scandia-stabilize zirconia," Solid State Ionics, 176(3-4), 261 (2005).

16. S. P. Jiang, "A review of wet impregnation - An alternative method for the fabrication of high performance and nano-structured electrodes of solid oxide fuel cells," Mater. Sci. Eng. A, 418(1-2), 199 (2006).

17. S. P. Jiang, S. Zhang, Y. Da Zhen, and W. Wang, "Fabrication and performance of impregnated Ni anodes of solid oxide fuel cells," J. Am. Ceram. Soc., 88(7), 1779 (2005).

18. A. N. Busawon, D. Sarantaridis, and A. Atkinson, "Ni infiltration as a possible solution to the redox problem of SOFC anodes," Electrochem. Solid-State Lett., 11, B186 (2008).

19. X. Liu, X. Meng, D. Han, H. Wu, F. Zeng, and Z. Zhan, "Impregnated nickel anodes for reduced-temperature solid oxide fuel cells based on thin electrolytes of doped $\mathrm{LaGaO}_{3}$, , J. Power Sources, 222, 92 (2013).

20. P. I. Cowin, C. T. G. Petit, R. Lan, J. T. S. Irvine, and S. Tao, "Recent progress in the development of anode materials for solid oxide fuel cells," Adv. Energy Mater., 1(3), 314 (2011).

21. P. Jasinski, T. Suzuki, V. Petrovsky, and H. U. Anderson, "Nanocomposite Nickel Ceria Cermet with Low Nickel Content for Anode-Supported SOFCs," Electrochem. Solid-State Lett., 8(4), A219 (2005).

22. M. Lomberg, E. Ruiz-Trejo, G. Offer, and N. P. Brandon, "Characterization of Niinfiltrated GDC electrodes for solid oxide cell applications," J. Electrochem. Soc., 161(9), F899 (2014)

23. T. Klemens $\varnothing$, K. Thydén, M. Chen, and H. J. Wang, "Stability of Ni-yttria stabilized zirconia anodes based on Ni-impregnation," J. Power Sources, 195(21), 7295 (2010).

24. K. Haberko, M. Jasinski, P. Pasierb, M. Radecka, and M. Rekas, "Structural and electrical properties of Ni - YSZ cermet materials," J. Power Sources, 195(17), 5527 (2010). 
25. H. Tu and U. Stimming, "Advances, aging mechanisms and lifetime in solid-oxide fuel cells," J. Power Sources, 127(1-2), 284 (2004).

26. H. Y. Chen, H. C. Yu, J. Scott Cronin, J. R. Wilson, S. A. Barnett, and K. Thornton, "Simulation of coarsening in three-phase solid oxide fuel cell anodes," J. Power Sources, 196(3), 1333 (2011).

27. D. Simwonis, F. Tietz, and D. Stover, "Nickel coarsening in annealed Ni / 8YSZ anode substrates for solid oxide fuel cells," Solid State Ionics, 132, 241 (2000).

28. M. Kishimoto, M. Lomberg, E. Ruiz-Trejo, and N. P. Brandon, "Enhanced triplephase boundary density in infiltrated electrodes for solid oxide fuel cells demonstrated by high-resolution tomography," J. Power Sources, 266, 291 (2014).

29. D. Kennouche, Y. K. Chen-Wiegart, C. Riscoe, J. Wang, and S. A. Barnett, "Combined electrochemical and X-ray tomography study of the high temperature evolution of Nickel - Yttria Stabilized Zirconia solid oxide fuel cell anodes," J. Power Sources, 307, 604 (2016).

30. E. C. Miller, Q. Sherman, Z. Gao, P. W. Voorhees, and S. A. Barnett, "Stability of Nickel-Infiltrated Anodes in Intermediate Temperature SOFCs," ECS Trans., 68(1), 1245 (2015)

31. S. Jung, C. Lu, H. He, K. Ahn, R. J. Gorte, and J. M. Vohs, "Influence of composition and $\mathrm{Cu}$ impregnation method on the performance of $\mathrm{Cu} / \mathrm{CeO}_{2} / \mathrm{YSZ}$ SOFC anodes," J. Power Sources, 154(1), 42 (2006).

32. A. Bertei, E. Ruiz-Trejo, F. Tariq, V. Yufit, A. Atkinson, and N. P. Brandon, "Validation of a physically-based solid oxide fuel cell anode model combining 3D tomography and impedance spectroscopy," Int. J. Hydrogen Energy, 41(47), 22381 (2016).

33. V. Rudnev, D. Loveless, R. L. Cook, and M. Black, Handbook of Induction Heating, CRC Press, 2002

34. S. B. Adler, "Mechanism and kinetics of oxygen reduction on porous $\mathrm{La} \mathrm{Sr} \mathrm{CoO}$ electrodes electrodes," Solid State Ionics, 111, 125 (1998).
35. A. Häffelin, J. Joos, M. Ender, A. Weber, and E. Ivers-Tiffé, "Time-Dependent 3D Impedance Model of Mixed-Conducting Solid Oxide Fuel Cell Cathodes," J. Electrochem. Soc., 160(8), F867 (2013).

36. D. Kennouche, Y. Karen Chen-Wiegart, J. Scott Cronin, J. Wang, and S. A. Barnett, "Three-Dimensional Microstructural Evolution of Ni- Yttria-Stabilized Zirconia Solid Oxide Fuel Cell Anodes At Elevated Temperatures," J. Electrochem. Soc., 160(11), 1293 (2013).

37. A. Leonide, V. Sonn, A. Weber, and E. Ivers-Tiffée, "Evaluation and Modeling of the Cell Resistance in Anode-Supported Solid Oxide Fuel Cells," J. Electrochem. Soc., 155(1), B36 (2008).

38. H. Zhu, A. Kromp, A. Leonide, E. Ivers-Tiffee, O. Deutschmann, and R. J. Kee, "A Model-Based Interpretation of the Influence of Anode Surface Chemistry on Solid Oxide Fuel Cell Electrochemical Impedance Spectra," J. Electrochem. Soc., 159(7), F255 (2012).

39. V. Sonn, A. Leonide, and E. Ivers-Tiffée, "Combined Deconvolution and CNLS Fitting Approach Applied on the Impedance Response of Technical Ni/8YSZ Cermet Electrodes," J. Electrochem. Soc., 155(7), B675 (2008).

40. S. Primdahl and M. Mogensen, "Gas Diffusion Impedance in Characterization of Solid Oxide Fuel Cell Anodes," J. Electrochem. Soc., 146(8), 2827 (1999).

41. S. Primdahl, "Gas Conversion Impedance: A Test Geometry Effect in Characterization of Solid Oxide Fuel Cell Anodes," J. Electrochem. Soc., 145(7), 2431 (1998).

42. T. Ramos, M. Søgaard, and M. B. Mogensen, "Electrochemical Characterization of Ni/ScYSZ Electrodes as SOFC Anodes," J. Electrochem. Soc., 161(4), 434 (2014).

43. A. J. L. Reszka, R. C. Snyder, and M. D. Gross, "Insights into the Design of SOFC Infiltrated Electrodes with Optimized Active TPB Density via Mechanistic Modeling," J. Electrochem. Soc., 161(12), F1176 (2014).

44. A. Bertei, J. G. Pharoah, D. A. W. Gawel, and C. Nicolella, "A Particle-Based Mode for Effective Properties in Infiltrated Solid Oxide Fuel Cell Electrodes," J. Electrochem. Soc., 161(12), F1243 (2014). 